\title{
Control of Contractile Properties Within Adaptive Ranges by Patterns of Impulse Activity in the Rat
}

\author{
Rolf H. Westgaarda and Terje Lømo \\ Institute of Neurophysiology, University of Oslo, 0162 Oslo 1, Norway
}

These experiments explore the relationship between patterned impulse activity and contractile properties of skeletal muscies. Soleus (SOL) and extensor digitorum longus (EDL) muscles of adult rats were denervated and stimulated directly from 4 to 15 weeks with the same number of pulse trains at different intratrain pulse frequencies $(1-500 \mathrm{~Hz})$, with different numbers of pulse trains (864-4,320,000 pulses/ d) at the same intratrain pulse frequencies, or with different combinations of pulse trains at 10 and $100 \mathrm{~Hz}$.

Chronic stimulation of the denervated SOL resulted in twitch times-to-peak and half-relaxation times that varied in a graded manner between values longer than those in the normal SOL to values as fast as those in the normal EDL, depending upon the pattern used. Increasing pulse frequencies (constant number) resulted in faster twitches, lower twitch/tetanus ratios, increasing post-tetanic potentiations, and larger tetanic tensions. Increasing pulse numbers (constant frequencies) resulted in slower twitches, lower twitch/tetanus ratios, post-tetanic depressions, and higher fatigue indices. The effect of varying the pulse number on twitch parameters was greater at low frequencies $(10-20 \mathrm{~Hz})$ than at high frequencies $(100 \mathrm{~Hz})$. SOL muscles receiving pulse trains at both 10 and $100 \mathrm{~Hz}$ became much faster than muscles receiving pulse trains at $10 \mathrm{~Hz}$ only, even in the experiments where the stimulation pattern contained 9 times as many pulses at 10 as at $100 \mathrm{~Hz}$.

Chronic stimulation of both the denervated and the innervated EDL with large numbers of pulses at 10 or $15 \mathrm{~Hz}$ resulted in twitches that were only half as slow as those induced in the SOL by the same "slow" patterns. In addition, these patterns led to a marked decrease in maximum tetanic tension and a marked increase in twitch/tetanus ratio. During stimulation with a small number of pulses at $150 \mathrm{~Hz}$, on the other hand, twitch speed, twitch/tetanus ratio, and maximum tetanic tension remained normal or almost normal.

We conclude that the isometric twitch and related properties of the rat SOL muscle can be graded within wide "adaptive ranges" by varying either the number or the fre-

\footnotetext{
Received Jan. 29, 1987; revised Feb. 26, 1988; accepted Mar. 1, 1988.

This work was supported by The Norwegian Research Council for Science and the Humanities and by The Muscular Dystrophy Association of America. We wish to thank Mrs. Sigrid Schaller for skilled technical assistance.

Correspondence should be addressed to Terje Lomo, Institute of Neurophysiology, Karl Johans gate 47, 0162 Oslo 1, Norway.

a Present address: Division of Work and Organization Sciences, University of Trondheim, 7034-Trondheim, Norway.
}

Copyright (C) 1988 Society for Neuroscience $0270-6474 / 88 / 124415-12 \$ 02.00 / 0$ quency of pulses. In the EDL, the corresponding adaptive ranges appear much narrower, suggesting that the EDL and the SOL contain intrinsically different muscle fibers.

In recent years it has become increasingly clear that impulse activity along neural pathways has long-term effects that are essential for normal development and functioning in the nervous system and the skcletal muscles that it inncrvates. These effects raise some questions that can be addressed by studying the neuromuscular system. First, does a certain effect depend on the frequency of impulses during activity, the amount of activity over time, or other characteristics of patterned activity? For example, motoneurons to fast and slow twitch muscles of the rat generate trains of impulses at high and low frequencies, respectively (Fischbach and Robbins, 1969; Hennig and Lomo, 1985). When fast-twitch muscles are stimulated chronically with low-frequency patterns, they become slowly contracting (Salmons and Vrbová, 1969; Pette et al., 1973; Salmons and Sréter, 1976). Conversely, when slow-twitch muscles are stimulated with a high-frequency pattern, they become rapidly contracting (Lømo et al., 1974, 1980; Smith, 1978; Hennig and Lømo, 1987a), suggesting that impulse frequency may play an important role in regulating contractile speed (Lømo, 1976). Others, however, find no evidence for pulse rate-specific effects on contraction speed and suggest that other characteristics, such as the daily amount or distribution of activity (Kernell et al., 1987) or the time allowed between contractions (Al-Amood and Lewis, 1987) are important. In this work, therefore, we extend our earlier analysis by stimulating rat soleus (SOL) muscles either with constant numbers of pulses at different frequencies (range, $1-500 \mathrm{~Hz}$ ), or with different numbers of pulses per day (range, $864-4,320,000)$ at constant frequency, and then measure the effects on isometric twitch speed and other parameters.

A second question concerns the possibility that impulse activity regulates cellular properties in different ways in different cells, owing to tissue-specific differences between the cells. Evidence for such differences between skeletal muscles has recently been obtained (Izumo et al., 1986; Hoh et al., in press). Therefore, we have activated extensor digitorum longus (EDL) and SOL muscles of the rat with identical stimulation patterns, expecting similar contractile speeds if their intrinsic properties are similar.

Finally, we ask whether neurons control the properties of their target cells primarily through the activity they evoke, or whether trophic substances from nerve terminals are also required. The answer to this question may be different in the nervous system, wherc the target cells contain only onc nucleus that directs the rest of the cell through elaborate ortho- and retrograde transport 
Table 1. Stimulation patterns used in this work

\begin{tabular}{|c|c|c|c|c|c|c|c|c|}
\hline $\begin{array}{l}\text { Pulse rate } \\
(\mathrm{Hz})\end{array}$ & Trains/min & Pulses & $\begin{array}{l}\text { Train } \\
\text { duration } \\
\text { (sec) }\end{array}$ & $\begin{array}{l}\text { Interval } \\
\text { between trains } \\
\text { (sec) }\end{array}$ & Pulses/d & $\begin{array}{l}\text { Total } \\
\text { stimulated } \\
\text { time } / 24 \mathrm{hr} \\
(\%)\end{array}$ & Pattern & $\begin{array}{l}\text { Symbols } \\
\text { used }\end{array}$ \\
\hline 1 & (continuous) & & & & 86,400 & & 1 & $\bullet$ \\
\hline 10 & 1 & 60 & 6.00 & 54.0 & 86,400 & 10.0 & 2 & $\bullet$ \\
\hline 20 & 1 & 60 & 3.00 & 57.0 & 86,400 & 5.0 & 3 & 0 \\
\hline 35 & 1 & 60 & 1.71 & 58.3 & 86,400 & 2.9 & 4 & 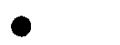 \\
\hline 50 & 1 & 60 & 1.20 & 58.8 & 86,400 & 2.0 & 5 & - \\
\hline 100 & 1 & 60 & 0.60 & 59.4 & 86,400 & 1.0 & 6 & $\bullet$ \\
\hline 300 & 1 & 60 & 0.20 & 59.8 & 86,400 & 0.3 & 7 & $\bullet$ \\
\hline 500 & 1 & 60 & 0.12 & 59.9 & 86,400 & 0.2 & 8 & $\bullet$ \\
\hline 10 & 1 & 540 & 54.00 & 6.0 & 777,600 & 90 & 9 & 0 \\
\hline 15 & 4 & 150 & 10.00 & 5.0 & 864,000 & 67 & 10 & 0 \\
\hline 20 & 2 & 200 & 10.00 & 20.0 & 576,000 & 33 & 11 & 0 \\
\hline 100 & 50 & 60 & 0.60 & 0.6 & $4,320,000$ & 50 & 12 & 0 \\
\hline 10 & 0.01 & 60 & 6.00 & 5994.0 & 864 & 0.10 & 13 & $\square$ \\
\hline 100 & 0.01 & 60 & 0.60 & 5999.4 & 864 & 0.01 & 14 & $\square$ \\
\hline 150 & 0.1 & 60 & 0.40 & 599.6 & 8640 & 0.07 & 15 & $\square$ \\
\hline $10+100$ & $1+0.01$ & $540+60$ & $54+0.6$ & $6+5994.4$ & $777,600+864$ & $90+0.01$ & 16 & $\mathbf{u}$ \\
\hline $10+100$ & $1+1$ & $540+60$ & $54+0.6$ & $6+59.4$ & $777,600+86,400$ & $90+1$ & 17 & $\Delta$ \\
\hline $10+100$ & $1+1$ & $60+60$ & $6+6$ & $6+6$ & $86,400+86,400$ & $1+1$ & 18 & $\nabla$ \\
\hline
\end{tabular}

All patterns except no. 15 were used for SOL. Only patterns 9, 10, and 15 were used for EDL. Pattern $16=$ pattern $9(10 \mathrm{~Hz})+$ pattern $13(100 \mathrm{~Hz})$. Pattern $17=$ pattern $9(10 \mathrm{~Hz})+$ pattern $6(100 \mathrm{~Hz})$. Pattern $18=$ pattern $2(10 \mathrm{~Hz})+$ pattern $6(100 \mathrm{~Hz})$.

systems, from in the skeletal muscles, where the target muscle fibers contain a large number of nuclei and no comparable transport systems have been demonstrated. Nevertheless, for many years the neuromuscular preparation has been much used for the study of neurotrophic control mechanisms. In these studies, the muscles have often been stimulated with the innervation intact. A consequence of this is that the muscles also receive activity and chemical signals from the motoneurons that may interfere with the effects of the stimulation. In this and other works, we have therefore stimulated denervated muscles to exclude all neural influences and to be able to determine precisely the pattern of activity imposed on the muscle. It is, then, of some interest to examine the extent to which certain stimulation patterns can restore normal contractile properties in the muscle and mimic the effects of reinnervation by different types of nerves, as demonstrated, for example, in the experiments by Close (1969) and Gutmann and Carlson (1975).

We conclude that in the SOL of the rat the twitch speed can be graded within certain limits (the adaptive range) through variations in either the amount or frequency of stimulation. In the EDL the adaptive range is narrower, suggesting that this muscle differs intrinsically from the SOL. Finally, appropriate stimulation patterns restore several normal properties in the denervated muscle and apparently completely mimic the effects of reinnervation by fast and slow motoneurons, indicating that motoneurons control the contractile properties of muscle primarily through the activity they evoke in the muscle.

\section{Materials and Methods}

Denervation and chronic stimulation. Young adult male Wistar rats, weighing $250-350 \mathrm{gm}$ at the beginning of the experiment, were anesthetized with Equithesin $(0.4 \mathrm{ml} / 100 \mathrm{gm}$ body weight, i.p.). The sciatic nerve was cut and reflected in the thigh on one or both sides to denervate
SOL and EDL for periods ranging from 28 to 106 days in SOL (mean, $55 \mathrm{~d}, n=63$ ) and $48-102 \mathrm{~d}$ in EDL (mean, $72 \mathrm{~d} ; n=9$ ). Two multistranded, Teflon-coated, stainless steel wires (OD, $0.3 \mathrm{~mm}$; AS 632, Cooner Sales Wire Co., Chatsworth, CA) without insulation at the ends were implanted into the right leg. The uninsulated end of one wire was placed proximally and posteriorly and the uninsulated end of the other wire distally and anteriorly across the SOL or the EDL. The wires were run under the skin to the head and into a flexible silicon tube (OD, $6 \mathrm{~mm}$ ) that was fixed to the skull with screws and dental cement. The wires and the protecting tube were connected to a rotating contact approximately $0.5 \mathrm{~m}$ above the rat, which could move freely in a large bucket.

Stimulation started $\mathbf{l} \mathbf{d}$ after denervation. The following stimulation patterns (see Table 1) were used: (1) patterns 1-8 (0) consisting of 60 pulses $/ 60 \mathrm{sec}$ (constant number) at frequencies ranging from 1 to 500 $\mathrm{Hz}$; (2) patterns 9-12 $(O)$ consisting of large numbers of pulses at 10 , 15,20 , or $100 \mathrm{~Hz}$; (3) patterns 13-15 (口) consisting of small numbers of pulses at 10,100 , or $150 \mathrm{~Hz}$; (4) patterns 16-18; consisting of 540 pulses at $10 \mathrm{~Hz} / 60 \mathrm{sec}$ plus 60 pulses at $100 \mathrm{~Hz} / 6000 \mathrm{sec}(\square)$ or every $60 \mathrm{sec}(\Delta)$, or 60 pulses at $10 \mathrm{~Hz} / 60 \mathrm{sec}$ alternating with 60 pulses at $100 \mathrm{~Hz} / 60 \mathrm{sec}(\nabla)$. Only some of these patterns (see Table 1) were used for the EDL. In 3 rats the sciatic nerve was not cut and the common fibular nerve stimulated through electrodes placed close to the nerve on the lateral side of the knee. The stimulus was always bipolar, with a duration of $0.2 \mathrm{msec}$ and an intensity of 5-10 $\mathrm{mA}$ for the denervated muscles or about $0.5 \mathrm{~mA}$ for the nerve. During the chronic stimulation the rats did not seem to have pain and they slept, ate, and put on weight apparently like rats without electrode implants.

Acute experiments. Under Equithesin anesthesia $(0.4 \mathrm{ml} / 100 \mathrm{gm}$ body weight, i.p.), the SOL or the EDL muscle was dissected free from most of the surrounding tissue, leaving the main blood supply intact. The muscles were not reinnervated, since electrical stimuli evoked clear contractions when applied directly to the muscle, and no contractions, as observed with the dissection microscope, when applied to the nerve trunk just outside the muscle. The leg was then inserted into a chamber, which was sealed with the skin around the thigh and filled with Ringer's solution kept oxygenated at $35^{\circ} \mathrm{C}$. A short thread connected the distal muscle tendon to a transducer that recorded isometric twitch and tetanic tensions at optimum length for twitch tension. Supramaximal stimulation was obtained by stimulating the muscle directly through 2 platinum plates placed close to the muscle surface, one on each side, using $0.5-1$-msec-long and up to 30 -mA-strong pulses. 

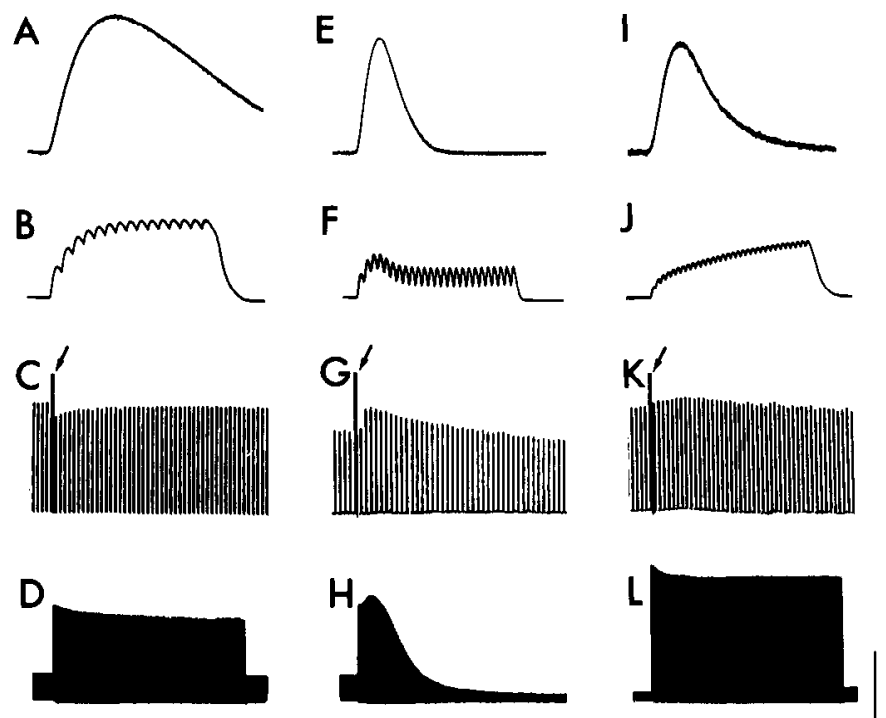

Figure 1. Contractile properties of 3 SOL muscles after approximately 2 months of denervation and direct stimulation. The stimulation consisted of many pulses per day at $15 \mathrm{~Hz}(A-D)$, few pulses per day at 100 $\mathrm{Hz}(E-H)$, and many pulses per day at $100 \mathrm{~Hz}(I-L)$, corresponding to patterns 10,13 , and 12, respectively, in Table 1 . Top row, isometric twitches. Second row, unfused tetanic contractions during stimulation at $15 \mathrm{~Hz}(B)$ and $25 \mathrm{~Hz}(F, J)$. Third row, single twitches $(0.33 \mathrm{~Hz})$ before and after tetanic stimulation at $200 \mathrm{~Hz}$ for $1 \mathrm{sec}$ (arrow). Last row, isometric tensions during stimulation, first at $1 \mathrm{~Hz}$ (single twitches), then at $77 \mathrm{~Hz}$ for $330 \mathrm{msec} / 1 \mathrm{sec}$ during $2 \mathrm{~min}$, and finally at $1 \mathrm{~Hz}$ again. Horizontal bar: $30 \mathrm{msec}$ (row 1); $600 \mathrm{msec}$ (row 2); $60 \mathrm{sec}$ (rows $3,4)$. Vertical bar: $4 \mathrm{gm}(I, K) ; 10 \mathrm{gm}(A, C, E, G) ; 40 \mathrm{gm}(J, L) ; 50$ gm $(B, D, F, H)$.

\section{Results}

\section{Denervated and directly stimulated SOL muscles}

Direct stimulation of denervated SOL muscles resulted in different contractile properties, depending on the stimulation pattern used. As illustrated by representative records in Figure 1, a large number of pulses at low frequency (pattern 10 in Table 1) resulted in a slow twitch $(A)$, post-tetanic depression of the twitch $(C)$, and high resistance to fatigue $(D)$, as also observed in normal SOL muscles. A small number of pulses at high frequency (pattern 14 in Table 1), on the other hand, resulted in a fast twitch $(E)$, "sag" in tension during an unfused tetanic contraction $(F)$, post-tetanic potentiation $(G)$, and low fatigue resistance $(H)$. All these properties are typical of fast fatiguesensitive motor units (Burke, 1981). Finally, a large number of pulses at high frequency (pattern 12 in Table 1) resulted in a relatively fast twitch $(I)$, no sag $(J)$, moderate and slowly developing post-tetanic potentiation $(K)$, and high fatigue resistance $(L)$. These effects are further documented in Table 2 and below.

Twitch speed. In an attempt to separate the effects of different frequencies and numbers of pulses, we first delivered 60 pulses/ $60 \mathrm{sec}$ at frequencies ranging from 1 to $500 \mathrm{~Hz}$. As shown in Figure $2 A(\bullet)$ the twitch time-to-peak decreased in a graded manner from about 30 to $11 \mathrm{msec}$ with increasing frequencies. But with increasing frequency the trains of 60 pulses became necessarily shorter in duration (Table 1), and this may have contributed to the effect. Then we increased the number of pulse trains, keeping the frequency within each train constant at 10 , 20 , or $100 \mathrm{~Hz}$, and found considerable increases in twitch timeto-peak (Fig. $2 A, \mathrm{O}$ ). Conversely, when we decreased the number

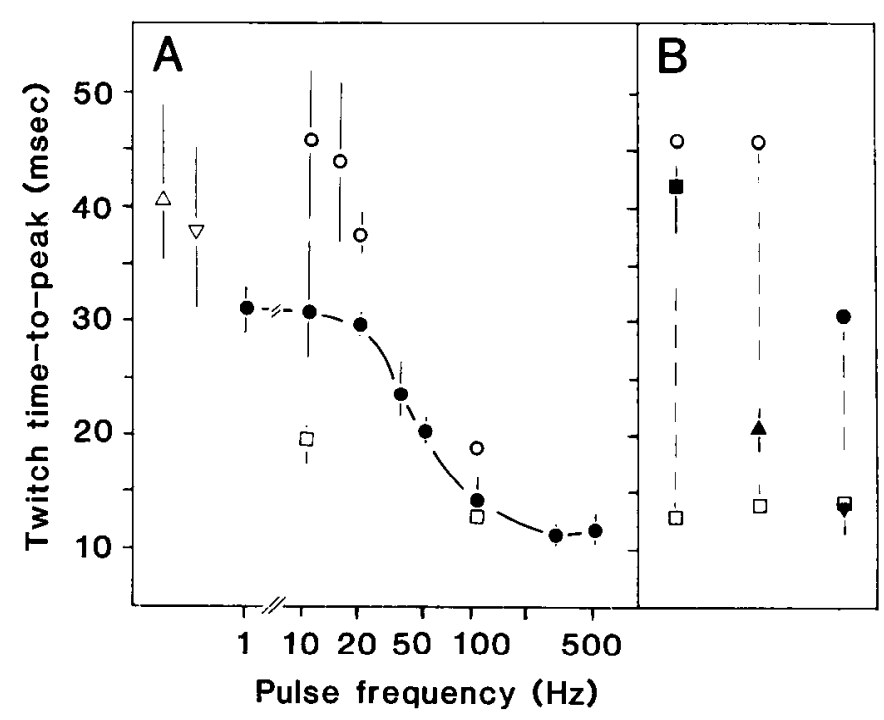

Figure 2. Twitch time-to-peak of SOL muscles after denervation and direct stimulation for 28-108 d. In $A$, the stimulation consisted of an intermediate number of pulses per day ( $(0$, patterns $1-8$ in Table 1$)$, a large number of pulses per day ( $O$, patterns $9-12$ in Table 1$)$, or a small number of pulses per day ( $\square$, patterns 13 and 14 in Table 1$)$ delivered in trains of pulses at the frequencies indicated along the abscissa. In $B$ pulse trains at 10 and $100 \mathrm{~Hz}$ had been combined either as a large number of pulses at $10 \mathrm{~Hz}$ plus a small number of pulses at $100 \mathrm{~Hz}(\mathbf{B}$, patterns 9 plus 13 in Table 1), a large number of pulses at $10 \mathrm{~Hz}$ plus an intermediate number of pulses at $100 \mathrm{~Hz}(\Delta$, patterns 9 plus 6 in Table 1), or an intermediate number of pulses at $10 \mathrm{~Hz}$ plus an intermediate number of pulses at $100 \mathrm{~Hz}(\nabla$, patterns 2 plus 6 in Table 1$)$. The effect of each $10 \mathrm{~Hz}$ pattern alone is indicated by $O$ and at the top of the interrupted lines and the effect of each $100 \mathrm{~Hz}$ alone by $\square$ at the bottom of these lines. Mean values for normally innervated $(\Delta ; n=$ $18)$ and denervated $(\nabla, n=10)$ are shown to the left in $A$. Vertical bars show total range of values. For the denervated and stimulated muscles, the number of muscles in each group varied between 2 and 10 (usually 3 or 4 ; see also Tables 2 and 3 ).

of pulse trains, the twitch time-to-peak decreased (Fig. $2 A$, $\square$ ). At $10 \mathrm{~Hz}$ the twitch time-to-peak varied between 19 and 45 msec for a 900 -fold difference in the number of pulse trains, and at $100 \mathrm{~Hz}$ bctween 13 and $19 \mathrm{msec}$ for a 5000 -fold difference. Thus, the "amount effect" appeared greater at low than at high frequencies. The twitch half-relaxation time changed in the same manner as the twitch time-to-peak (Table 2). Thus, the entire time course of the twitch ("twitch speed") was markedly affected by altered activity, apparently in a graded manner and within certain limits. Denervation alone reduced the twitch time-to-peak and half-relaxation time, but the effect was small (Fig. 2A, $\nabla$; Table 2).

In an attempt to further separate the effects of different frequencies and numbers of pulses, we added trains of pulses at $100 \mathrm{~Hz}$ to trains of pulses at $10 \mathrm{~Hz}$. We then asked whether the twitch would become slower because of the increased number of pulses or faster because of the increased frequency of pulses. As shown in Figure $2 B, \Delta$; addition of 60 pulses $/ 60 \mathrm{sec}$ at 100 $\mathrm{Hz}$ to 9 times as many pulses $(540 / 60 \mathrm{sec}$ ) at $10 \mathrm{~Hz}$ (pattern 17 in Table 1) reduced the mean twitch time-to-peak from 45 to $21 \mathrm{msec}$, whereas in the absence of $10 \mathrm{~Hz}$ stimulation, the 100 $\mathrm{Hz}$ pattern resulted in a twitch time-to-peak of $14 \mathrm{msec}$. The effect of $100 \mathrm{~Hz}$ stimulation almost disappeared when we reduced the $100 \mathrm{~Hz}$ stimulation to 60 pulses $/ 6000 \mathrm{sec}$ (Fig. $2 B$, D; pattern 16 in Table 1). Now the twitch time-to-peak remained long $(41 \mathrm{msec})$, although in the absence of $10 \mathrm{~Hz}$ stimulation 
Table 2. Contractile properties of denervated and stimulated SOL muscles

\begin{tabular}{|c|c|c|c|c|c|c|c|c|}
\hline Pattern & $\begin{array}{l}\text { Pulse rate } \\
(\mathrm{Hz})\end{array}$ & Pulses/d & $\begin{array}{l}\text { Twitch } \\
\text { time-to- } \\
\text { peak } \\
\text { (msec) }\end{array}$ & $\begin{array}{l}\text { Twitch } \\
\text { half- } \\
\text { relax. } \\
\text { time } \\
\text { (msec) }\end{array}$ & $\begin{array}{l}\text { Fatigue } \\
\text { index }\end{array}$ & $\begin{array}{l}\text { Muscle } \\
\text { weight } \\
\text { (mg) }\end{array}$ & $\begin{array}{l}\text { Tetanic } \\
\text { tension/ } \\
\text { muscle } \\
\text { weight } \\
(\mathrm{gm} / \mathrm{mg})\end{array}$ & $\begin{array}{l}\text { Number } \\
\text { of } \\
\text { muscles }\end{array}$ \\
\hline 1 & 1 & 86,400 & 30.3 & 35.2 & 0.60 & 71 & 0.41 & 3 \\
\hline 2 & 10 & 86,400 & 30.1 & 35.2 & 0.63 & 67 & 0.61 & 4 \\
\hline 3 & 20 & 86,400 & 29.0 & 37.5 & 0.66 & 89 & 0.51 & 2 \\
\hline 4 & 35 & 86,400 & 23.0 & 24.3 & 0.59 & 97 & 0.84 & 3 \\
\hline 5 & 50 & 86,400 & 19.8 & 20.0 & 0.56 & 99 & 0.81 & 4 \\
\hline 6 & 100 & 86,400 & 15.0 & 19.6 & 0.58 & 113 & 0.97 & 8 \\
\hline 7 & 300 & 86,400 & 11.2 & 13.0 & 0.26 & 126 & 0.74 & 3 \\
\hline 8 & 500 & 86,400 & 11.8 & 14.5 & 0.30 & 147 & 0.71 & 2 \\
\hline 9 & 10 & 777,600 & 44.7 & 75.8 & 0.67 & 107 & 0.62 & 3 \\
\hline 10 & 15 & 864,000 & 42.8 & 75.4 & 0.68 & 124 & 0.58 & 5 \\
\hline 11 & 20 & 576,000 & 36.7 & 41.7 & 0.43 & 112 & 0.80 & 3 \\
\hline 12 & 100 & $4,320,000$ & 18.5 & 24.3 & 0.83 & 124 & 0.70 & 4 \\
\hline 13 & 10 & 864 & 19.0 & 21.2 & 0.21 & 96 & 0.61 & 3 \\
\hline 14 & 100 & 864 & 13.3 & 13.2 & 0.10 & 83 & 0.46 & 3 \\
\hline 16 & $10+100$ & $777,600+864$ & 41.0 & 76.0 & 0.82 & 100 & 0.70 & 4 \\
\hline 17 & $10+100$ & $777,600+86,400$ & 21.2 & 25.1 & 0.79 & 102 & 0.57 & 5 \\
\hline 18 & $10+100$ & $86,400+86,400$ & 14.2 & 15.1 & 0.30 & 111 & 1.01 & 4 \\
\hline Normal & & & 41.0 & 56.4 & 0.71 & 168 & 1.09 & 10 \\
\hline Denervated & & & 37.6 & 44.2 & 0.56 & 29 & 0.12 & 10 \\
\hline
\end{tabular}

Denervation and stimulation lasted from 28 to $106 \mathrm{~d}$. Only mean values are given. See Table 1 for details of the stimulation patterns used.

this $100 \mathrm{~Hz}$ pattern resulted in a twitch time-to-peak of $13 \mathrm{msec}$. Finally, 60 pulses at $10 \mathrm{~Hz} / 60 \mathrm{sec}$ alternated with 60 pulses at $100 \mathrm{~Hz} / 60 \mathrm{sec}$ (Fig. $2 B$, $\nabla$; pattern 18 in Table 1). In this case, the stimulation at $10 \mathrm{~Hz}$ was without effect and the twitch timeto-peak became as short as with $100 \mathrm{~Hz}$ stimulation alone (14 msec). All these combinations of 10 and $100 \mathrm{~Hz}$ stimulation altered the twitch half-relaxation time in the same way as they altered the twitch time-to-peak (Table 2). These results suggest that frequency and number of muscle impulses have separate effects on the twitch speed of rat SOL muscles. When the number of impulses is large, signals are generated that make the muscle slow. When the frequency is high, signals are generated that make the muscle fast. And when large numbers of pulses at low frequency are applied together with small numbers of pulses at high frequencies, the signals from the 2 patterns apparently interact to induce an intermediate contraction speed. Furthermore, for equal numbers of pulses, the fast pattern appears more effective than the slow pattern. High-frequency stimulation also removes supersensitivity to acetylcholine from denervated rat SOL muscles more rapidly than does low-frequency stimulation (Lomo and Westgaard, 1975).

Time course. It is important to know whether the muscles were still undergoing transformation when they were examined 28-106 d after denervation and onset of stimulation. Plots of twitch time-to-peak against the duration of the period of chronic stimulation for each stimulation pattern did not indicate any time-dependent changes (not shown). In a more complete time course study, essentially all of the increase in twitch speed during $100 \mathrm{~Hz}$ stimulation of dencrvated SOL muscles occurred during the first of up to 4 months of stimulation (Gorza et al., 1988). Therefore, the different SOL twitch speeds obtained in the present work were probably stable end-points at the time of measurement.
Twitch/tetanus ratio. Stimulation had marked effects on the twitch/tetanus ratio (Fig. 3). Low frequencies, like denervation, resulted in a high twitch/tetanus ratio that decreased to very low values when the frequency within each train of 60 pulses was increased from 1 to $500 \mathrm{~Hz}$ (Fig. $3 \mathrm{~A}$, O). Since such stimulation also resulted in progressively faster twitches (Fig. $2 A$, O), twitch/tetanus ratio and twitch time-to-peak became positively correlated (Fig. $3 B, 0$ ). But the twitch/tetanus ratio was also influenced by the number of pulses, since increasing numbers resulted in lower twitch/tetanus ratios (Fig. $3 A, \mathrm{O}$ ) and decreasing numbers in higher twitch/tetanus ratios (Fig. 3A, $\square$ ) at constant stimulation frequencies. This altered the slopes for the linear correlations betwecn twitch/tctanus ratio and twitch time-to-peak (Fig. 3B). In addition, it is clear from Figure $3 B$, that muscles with the same time-to-peak can have widely different twitch/tetanus ratios depending on how they are stimulated.

Post-tetanic potentiation. Following brief tetanic contractions the isometric twitch is transiently increased in size in the normal EDL (post-tetanic potentiation) but transiently decreased in size in the normal SOL (post-tetanic depression; Close and Hoh, 1969). In the final acute experiments of the present study, we directly stimulated the muscle supramaximally once every $3 \mathrm{sec}$ before and after a tetanus at 100-200 $\mathrm{Hz}$ lasting $1 \mathrm{sec}$. SOL muscles that had been chronically stimulated with increasing frequencies (constant number of pulses) showed increasingly more pronounced post-tetanic potentiations (Fig. $4 A$, ๑). But post-tetanic potentiation, like twitch/tetanus ratio, also depended on the number of pulses. At constant frequencies, more pulse trains either reduced the potentiation or induced posttetanic depression (Fig. $4 A, 0$ ), while fewer pulse trains had the opposite effect (Fig. $4 A, \square$ ). Thus, post-tetanic potentiation was counteracted by both low frequencies and large numbers of 

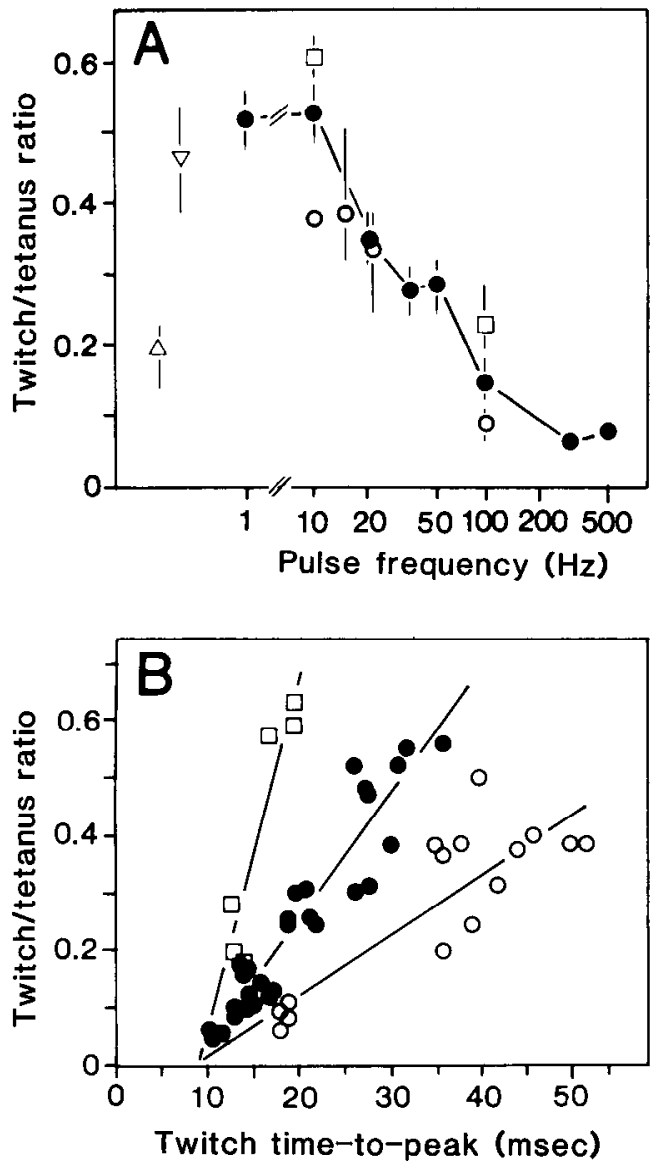

Figure 3. Twitch/tetanus ratios of denervated and chronically stimulated SOL muscles plotted against stimulation frequency $(A)$ and against twitch time-to-peak $(B)$. Same muscles and symbols as in Figure $2 A$. The chronic stimulation consisted of small $(\square)$, intermediate $(\Theta)$, and large $(O)$ numbers of pulses per day at the frequencies indicated in $A$. The twitch/tetanus ratio was measured at the beginning of each experiment, when the twitch was unpotentiated.

pulses. On the other hand, when SOL muscles were stimulated at low frequencies $(1,10$, or $20 \mathrm{~Hz})$ with an intermediate number of pulses (60 pulses $/ 60 \mathrm{sec}$ ), the twitches were first depressed (Fig. $4 A$, O) for up to $10 \mathrm{sec}$ after the tetanus and then potentiated (Fig. $43 A$, $)$ ). That brief tetanic stimulations may first depress and then potentiate the subsequent twitches has, as far as we know, not previously been described. The finding suggests that post-tetanic depression and potentiation may arise from separate processes within the muscle fiber.

Increasing stimulation frequencies (constant number) resulted in greater post-tetanic potentiations (Fig. $4 A$ ) and smaller twitch/ tetanus ratios (Fig. $3 A$ ), and, as a consequence of this, in a negative correlation between these 2 parameters (Fig. $4 B, 0$ ). This is consistent with the hypothesis that lower twitch/tetanus ratios reflect less complete activation during a twitch (Duchateau and Hainaut, 1986). But post-tetanic potentiation also depended on the number of pulses, so that the relation between potentiation and twitch/tetanus ratio was shifted toward lower values of potentiation when the pulse number was increased (Fig. $4 B, O$ ) and toward higher values of potentiation when the pulse number was decreased (Fig. $4 B, \square$ ). As a result, large differences in potentiation were observed for the same twitch/ tetanus ratio, suggesting that twitch potentiation does not de-
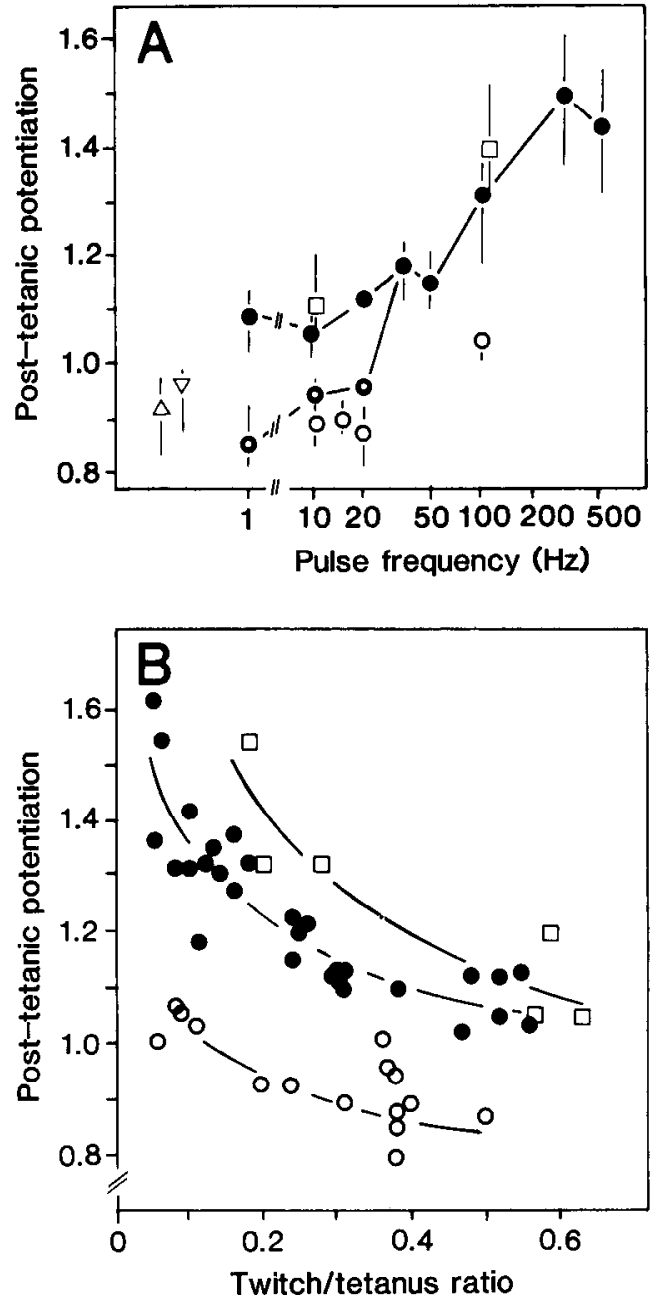

Figure 4. Post-tetanic depressions and potentiations of denervated and chronically stimulated SOL muscles plotted against stimulation frequency $(A)$ and against twitch/tetanus ratio $(B)$. Same muscles and symbols as in Figure $2 A$. The chronic stimulation consisted of small ( $\square$ ), intermediate $(O)$, and large $(O)$ numbers of pulses per day at the frequencies indicated in $A$. At 1,10 , and $20 \mathrm{~Hz}$ in $A$, the twitch was first depressed $(0)$ and then potentiated $(\bullet)$ after the tetanus. In $B$, only the potentiated values are plotted for these muscles. The value for posttetanic depression or potentiation (ordinate) was obtained by dividing the amplitude of smallest or largest isometric twitch after a $1 \mathrm{sec}$ tetanus at $200 \mathrm{~Hz}$ by the mean amplitude of 5 preceding control twitches (see Fig. $1, C, G, K$ ).

pend only on the level of activation, as indicated by the twitch/ tetanus ratio (see Discussion).

Tension-frequency relation. Stimulation had marked effects on the tension-frequency curve of SOL muscles (Fig. 5), as expected from the effects on twitch time-to-peak and half-relaxation time (twitch duration). Tension-frequency curves have a steep part where rate modulation of muscle force output is most efficient and, as shown in Figure $5 A$, this part moved markedly to the right (toward the imposed frequency) as the chronic stimulation frequency (constant number) was increased. Through such movements, the rate control mechanism of muscle force output, which is most efficient around the frequencies that correspond to the steepest part of the tension-frequency curve, may adapt to different types of imposed activity. Such adaptation may contribute to the match that exists in normal muscles between motoneuronal firing rate and twitch speed 


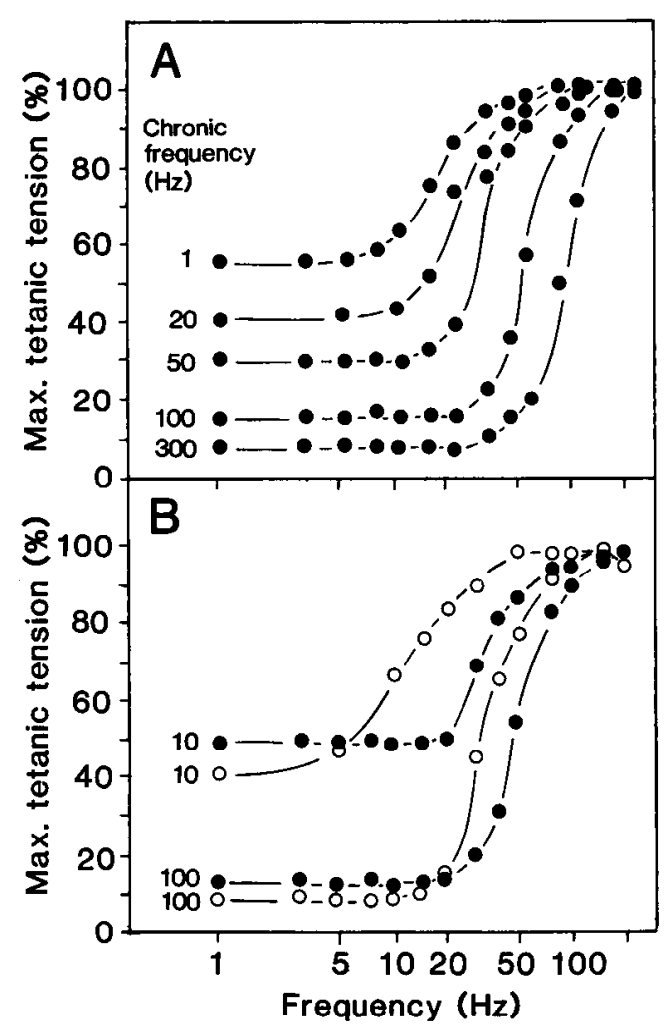

Figure 5. Tension-frequency curves of denervated and chronically stimulated SOL muscles. The curves were obtained in final acute experiments by stimulating the SOL in situ for $1 \mathrm{sec}$ at different frequencies. The tensions were then expressed as percentages of maximum tetanic tension and plotted against these frequencies (abscissa). The frequencies used during the chronic stimulation are indicated to the left of each curve, with an intermediate number of pulses per day indicated by (patterns $1-3,5-7$ in Table 1) and a large number of pulses per day by $O$ (patterns 9 and 12 in Table 1). Each symbol is mean of 3-10 muscles.

(Kernell, 1979; Hennig and Lomo, 1985). But the tension-frequency curve was also influenced by the number of pulses, as seen in Figure $5 B$, where the steep part moved to the left when the number of pulses at constant frequency was increased. This was expected from the slowing effect of large numbers of pulses on twitch duration (see above). One result of this movement is that slow muscles, which are also tonically active, will produce more force at the prevailing frequency (see Discussion).

Muscle tension. Stimulation had marked effects on muscle force production. Increasing frequencies (constant number) led to shorter twitch times-to-peak (Fig. $2 A$, O) and higher tetanic tensions, and this resulted in a negative correlation between tetanic tension and twitch time-to-peak (Fig. 6 $\mathrm{A}$, O). In contrast, twitch tension decreased as the twitch time-to-peak decreased during high-frequency stimulation (Fig. $6 A, \uparrow$ ). Therefore, the low twitch/tetanus ratio of muscles stimulated at high frequency (Fig. 3) is due partly to an increase in tetanic tension and partly to a decrease in twitch tension. But muscle tension, and particularly tetanic tension, was also influenced by the number of pulses. In Figure $6 B$ the muscles had been stimulated with large numbers of pulses at low frequency $(10-20 \mathrm{~Hz})$. These muscles had higher tetanic tensions and longer twitch times-to-peak (35$55 \mathrm{msec}$ ) than those muscles in Figure $6 \mathrm{~A}$ that had been stimulated with a much smaller number of pulses at $10-20 \mathrm{~Hz}$ and had twitch times-to-peak between 26 and 37 msec.
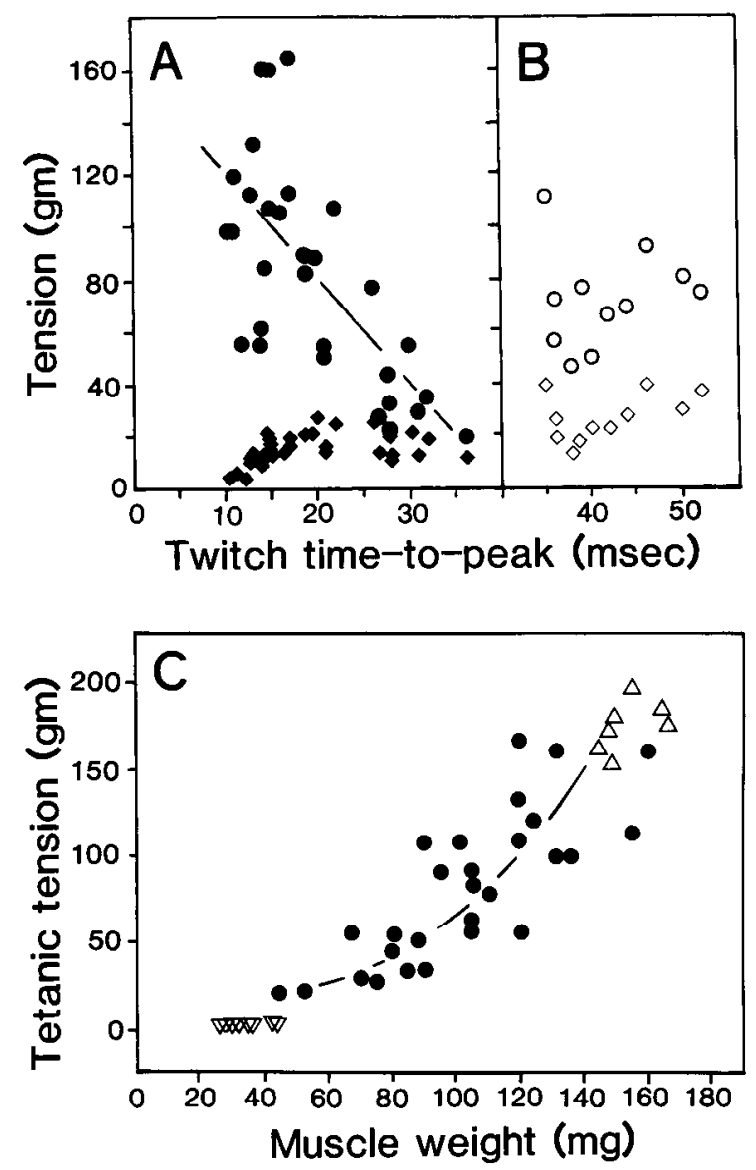

Figure 6. Muscle tension of denervated and chronically stimulated SOL muscles. In $A$, twitch tension ( $\bullet$ ) and maximum tetanic tension (๑) from muscles stimulated chronically with an intermediate number of pulses per day at frequencies ranging from 1 to $500 \mathrm{~Hz}$ (patterns 18 in Table 1) are plotted against twitch time-to-peak. In $B$ are plotted twitch tension $(\diamond)$ and maximum tetanic tension $(O)$ from muscles stimulated chronically with a large number of pulses at 10,15 , or 20 $\mathrm{Hz}$ (patterns 9,10 , and 11 in Table 1 ). In $C$, maximum tetanic tensions from innervated $(\Delta)$ and dencrvated $(\nabla)$ control muscles, and from denervated muscles stimulated with an intermediate number of pulses per day at frequencies ranging from 1 to $500 \mathrm{~Hz}(0$, patterns $1-8$ in Table 1) are plotted against muscle weight.

Denervated and stimulated SOL muscles produced more tetanic tension than did denervated and unstimulated SOL muscles (Fig. $6 \mathrm{C}$ ). The increase in tetanic tension was accompanied by an increase in muscle weight (Fig. 6C), and, since high frequencies produced the largest tetanic tensions, high frequencies were also more effective than low frequencies in counteracting denervation atrophy. In addition, there was a tendency for tetanic tension to increase more than muscle weight at high frequencies, suggesting that high frequency may also increase specific tetanic tension. This tendency is even stronger than is suggested by Figure $6 C$ because intermittent high-frequency stimulation (like cross-reinnervation with a fast nerve; Close, 1969; Barany and Close, 1971) leads to a considerable increase in fiber length (Gorza et al., 1988), which will increase the weight but not the cross-sectional area of the muscles.

The denervated and stimulated muscles produced less tetanic tension than did normal SOL muscles (Fig. $6 \mathrm{C}$ ), perhaps in part because of local injury and ineffective stimulation of some of the fibers (see Discussion). Presumably, the muscles with the largest tetanic tensions were also "best"-stimulated and, for 


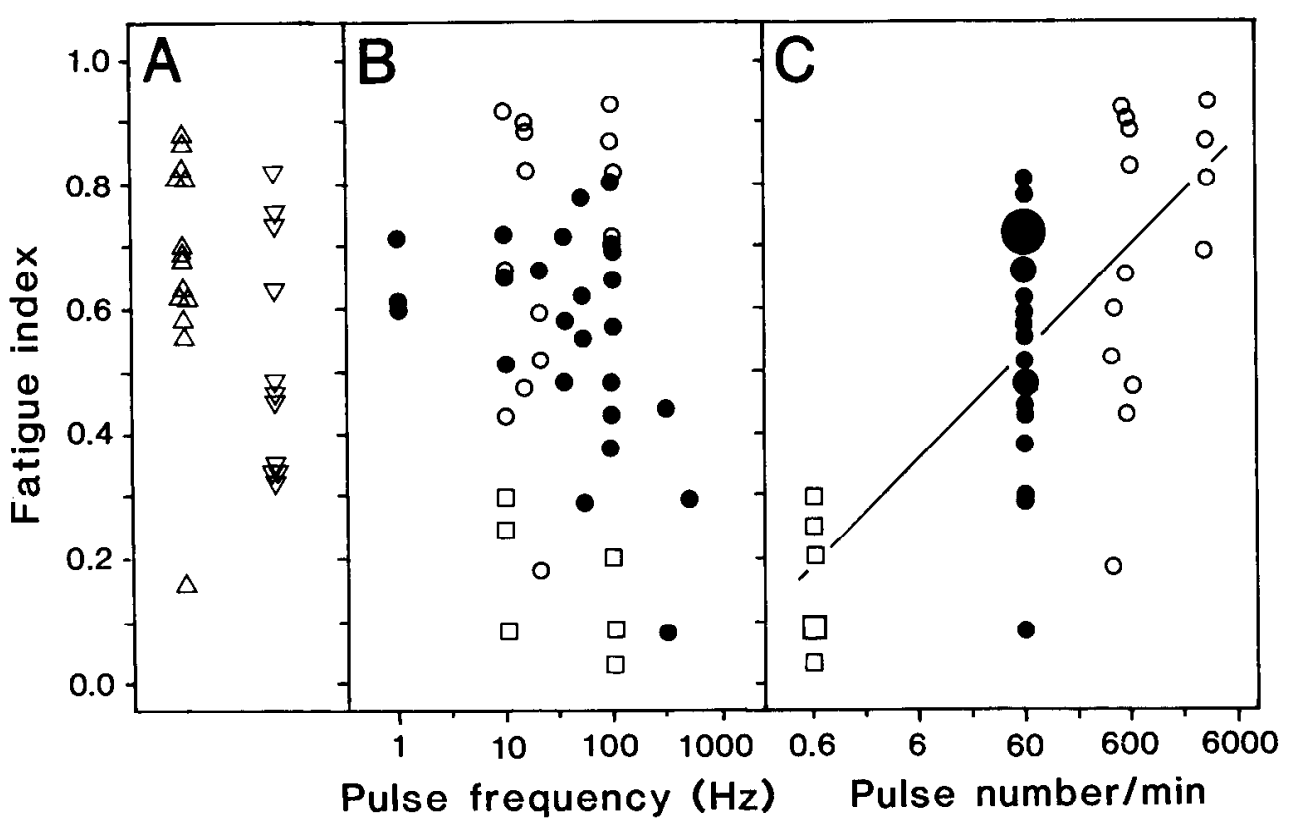

Figure 7. Fatigue index of normal $(\Delta)$ and denervated $(\nabla)$ control SOL muscles and of denervated and chronically stimulated SOL muscles. Same muscles and symbols as in Figure $2 A$. In $B$, the fatigue index is plotted against pulse rate within each pulse train regardless of the total number of pulses. In $C$, the fatigue index is plotted against total number of pulses per minute regardless of the pulse rate. The number of pulses per day was either small $(\square)$, intermediate $(\bullet)$, or high (O; see Table 1). these muscles, the tetanic tensions were within the normal range and about 100 times greater than those in denervated, unstimulated muscles. Thus, under optimal conditions, direct stimulation may largely counteract the atrophy induced by denervation alone.

Fatigue resistance. The fatigue index measured the ratio between tetanic tension at the end and at the beginning of 2-minlong series of tetanic stimulations (Burke et al., 1973). Each tetanus consisted of pulses at $77 \mathrm{~Hz}$, lasted $330 \mathrm{msec}$, and was repeated once every second (see Fig. 1). As shown in Figure 7, the fatigue index increased with increasing numbers of pulses (Fig. $7 C$ ), but did not show any clear relation to the frequency of stimulation (Fig. $7 B$ ), in contrast to the muscle properties described above. The fatigue index, however, varied considerably among similarly treated muscles, probably because some of the muscles became ischemic at the end of the fatigue test. In particular, the very low fatiguc index in one of the normal control muscles (Fig. $8 \mathrm{~A}$ ) and in some of the denervated and stimulated muscles (Fig. $7 C$ ) was probably due to ischemia.

\section{Denervated and directly stimulated EDL muscles}

In the denervated EDL, stimulation at high frequency prevented the increase in twitch time-to-peak (Fig. $8 \mathrm{~A}$ ), twitch half-relax- ation time (Table 3), and twitch/tetanus ratio (Fig. $8 B$ ) that occurred after denervation alone. Post-tetanic potentiation became greater than normal (Fig. $8 \mathrm{C}$ ) and maximum tetanic tension lower than normal but greater (about 10 times) than after denervation alone (Fig. $8 D$ ). In contrast, large numbers of pulses at low frequency resulted in slower twitches (Fig. 8A, O; Table 3 ), but the twitches did not become any slower than after denervation alone (Fig. 8A, $\nabla$; Table 3 ) and not nearly as slow as in the SOL stimulated with identical patterns (Fig. 2, O). In addition, large numbers of pulses at low frequency resulted in a marked decrease in tetanic tension (Fig. $8 D, 0$ ).

\section{Innervated EDL muscles stimulated through the nerve}

Large numbers of pulses at $10-15 \mathrm{~Hz}$ maintained a slow twitch in the denervated SOL, but failed to induce a similarly slow twitch in the denervated EDL (Tables 2 and 3; Eken and Gundersen, 1988). This was surprising because, in the rabbit, the innervated EDL becomes at least as slow as the SOL during similar stimulation of the nerve (Salmons and Sréter, 1976). To examine the role of innervation, we therefore stimulated the common peroneal nerve in rats with the same patterns. As shown in Figure $8(\odot)$ and Table 3, stimulation through the nerve had essentially the same effects as direct stimulation of

Table 3. Contractile properties of chronically stimulated EDL muscles

\begin{tabular}{|c|c|c|c|c|c|c|c|c|}
\hline Pattern & $\begin{array}{l}\text { Pulse rate } \\
(\mathrm{Hz})\end{array}$ & Pulses/d & $\begin{array}{l}\text { Twitch time- } \\
\text { to-peak } \\
\text { (msec) }\end{array}$ & $\begin{array}{l}\text { Twitch half- } \\
\text { relax. time } \\
\text { (msec) }\end{array}$ & $\begin{array}{l}\text { Fatigue } \\
\text { index }\end{array}$ & $\begin{array}{l}\text { Muscle } \\
\text { weight } \\
\text { (mg) }\end{array}$ & $\begin{array}{l}\text { Tetanic } \\
\text { tension/ } \\
\text { muscle } \\
\text { weight } \\
(\mathrm{gm} / \mathrm{mg})\end{array}$ & $\begin{array}{l}\text { Number } \\
\text { of } \\
\text { muscles }\end{array}$ \\
\hline 9 & 10 & 777,600 & 22.5 & 24.5 & 0.78 & 69 & 0.68 & 2 \\
\hline 10 & 15 & 864,000 & 20.9 & 19.0 & 0.46 & 74 & 0.83 & 5 \\
\hline 15 & 150 & 8640 & 11 & 12.5 & & 175 & 1.20 & 1 \\
\hline $10^{a}$ & 15 & 864,000 & 22.8 & 25.2 & 0.75 & 115 & 0.95 & 3 \\
\hline Normal & & & 11.9 & 10.6 & 0.20 & 189 & 1.42 & 7 \\
\hline Denervated & & & 22.3 & 27.7 & 0.66 & 38 & 0.42 & 5 \\
\hline
\end{tabular}

Denervation and stimulation lasted from 48 to $102 \mathrm{~d}$. Only mean values are given.

a 10: Innervation was intact and pattern 10 was applied through the nerve. 

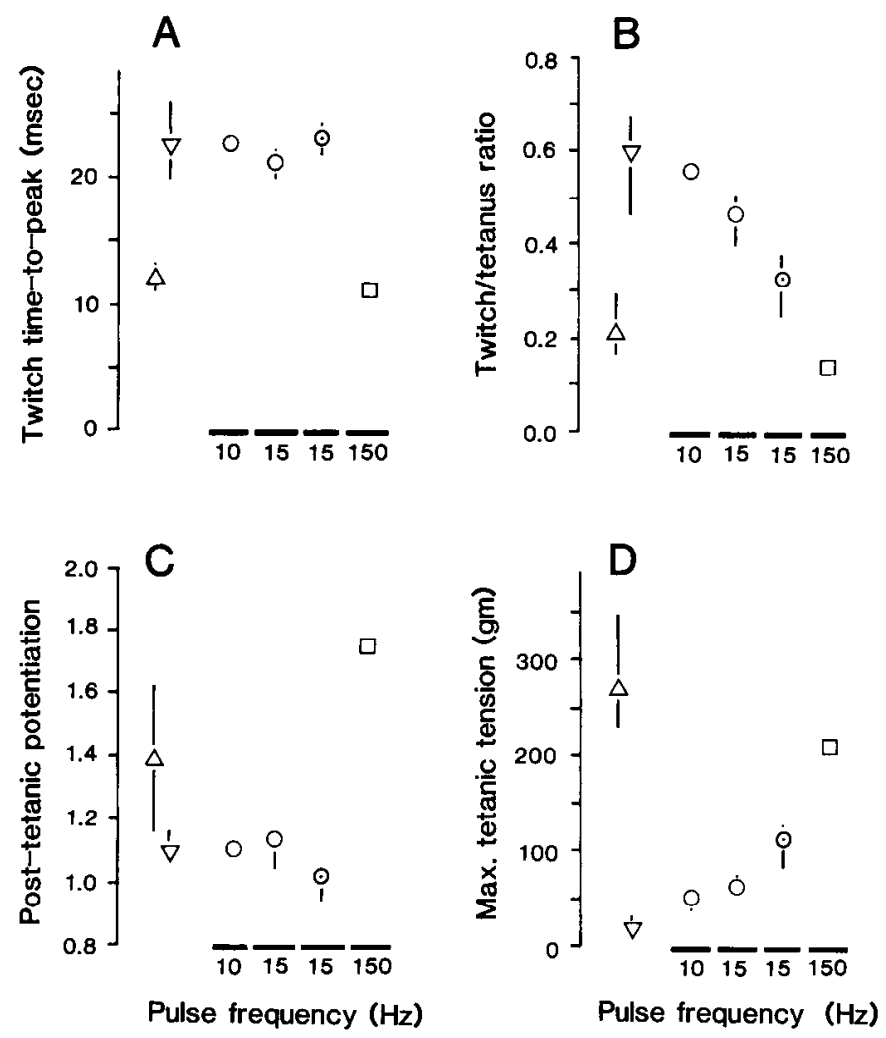

Figure 8. Twitch time-to-peak $(A)$, twitch/tetanus ratio $(B)$, post-tetanic potentiation $(C)$, and maximum tetanic tension $(D)$ of EDL muscles. The muscles had been denervated and stimulated for 48-102 d with a large number of pulses at 10 or $15 \mathrm{~Hz}(0$, patterns 9 and 10 in Table 1), or with small numbers of pulses at $150 \mathrm{~Hz}$ ( $\square$, pattern 15 in Table 1), or left innervated and stimulated through the peroneal nerve with a large number of pulses at $15 \mathrm{~Hz}(\odot$, pattern 10 in Table 1). Innervated $(\Delta, n=7)$ and denervated $(\nabla ; n=6)$ control muscles are shown to the left in each plot. Mean and total range of values are indicated.

the muscle after denervation did on twitch time-to-peak, halfrelaxation time, and post-tetanic potentiation. However, the twitch/tetanus ratio was lower and the maximum tetanic tension higher in muscles that had been stimulated through the nerve (Fig. 8, B, D). On the other hand, the denervated EDL generated much more tetanic tension after stimulation with a small number of pulse trains at $150 \mathrm{~Hz}$ (Fig. $8 D, \square$ ) than the innervated EDL did after stimulation through the nerve with large numbers of pulses at low frequency (Fig. $8 D, \odot$ ).

\section{Discussion}

Twitch speed is regulated within "adaptive ranges"

A main result of this work is the finding that the isometric twitch speed of denervated rat SOL muscles can be graded within wide limits by different patterns of direct stimulation. For the twitch time-to-peak, the lower and upper limits appeared close to 11 and $45 \mathrm{msec}$, respectively, and for the half-relaxation time close to 13 and $75 \mathrm{msec}$. From the literature, it appears that all types of manipulations affecting the twitch of rat SOL muscles result in twitch time-to-peak and half-relaxation times well within these limits. Therefore, these limits may represent adaptive ranges within which the twitch speed of rat SOL muscles can be graded by evoked muscle activity. Similar adaptive ranges were obtained for twitch/tetanus ratio and post-tetanic potentiation or depression of the twitch. In the EDL the range for the twitch time-to-peak appeared to extend from about 11 to $23 \mathrm{msec}$, and for the twitch half-relaxation time from about 12 to $25 \mathrm{msec}$. But these values are less certain as limiting values because the EDL was stimulated with fewer stimulation patterns.

\section{Regulation of twitch speed by frequency and number of impulses}

The twitch time-to-peak and half-relaxation times of the SOL could be graded by varying either the number of pulses or the frequency. Large numbers had a slowing effect that was greatest at the low frequencies $(10-20 \mathrm{~Hz})$ typical of normal SOL motor units (Hennig and Lomo, 1985). At $10 \mathrm{~Hz}$, the mean twitch time-to-peak declined from 45 to $19 \mathrm{msec}$ as the number of pulses was reduced from $4,320,000$ to $864 / \mathrm{d}$. This "amount effect" may explain, at least in part, why limb immobilization (Fischbach and Robbins, 1969; Mayer et al., 1981), transection of the spinal cord (Gallego et al., 1978; Mayer et al., 1984), and transection of the nerve to antagonistic muscles (Guth and Wells, 1972; Hennig, 1987) result in faster SOL twitches, since all these procedures probably reduce the amount of activity evoked by SOL motoneurons. A slowing effect of large amounts of activity seems advantageous in postural muscles such as the SOL because less energy is then required for maintaining muscle force output (Crow and Kushmerick, 1982). In addition, fewer fibers may be required to produce a given force, since each fiber will produce a larger fraction of its maximal tetanic force as the slowing effect of large amounts of activity moves the steep part of the tension-frequency curve to the left of the prevailing frequency (see Fig. $5 B$ ).

In our experiments, increases in the pulse frequency within each train also resulted in shorter trains and longer intervals between the trains (Table 1). Therefore, we cannot unequivocally attribute the faster twitches to the increase in frequency per se. On the other hand, when the $100 \mathrm{~Hz}$ pulse trains were delivered at intervals of either $6000 \mathrm{sec}$ (about $1 \mathrm{hr}, 40 \mathrm{~min}$ ), $60 \mathrm{sec}$, or $0.6 \mathrm{sec}$, the twitch became much faster than normal (Fig. 2), although the number of pulses varied 5000 -fold and the duration of intervals between trains 10,000 fold (Table 1). This suggests that the increase in twitch speed depended mainly on the high frequency used. The twitches also became much faster when $100 \mathrm{~Hz}$ pulse trains were added to $10 \mathrm{~Hz}$ pulse trains, even though this increased the number of trains and shortened the duration of the intervals between trains. This last result also shows that patterns inducing either fast or slow twitches, when applied alone, somehow interact within the fiber to produce twitches of intermediate speed when applied in combination.

In contrast, $\mathrm{Al}$-Amood and Lewis (1987) conclude that twitch speed may be determined by the time allowed between contractions and not by the pulse frequency during contractions. They stimulated denervated rat SOI muscles at frequencies ranging from 10 to $100 \mathrm{~Hz}$ and, unlike us, obtained almost the same twitch time-to-peak (about $22 \mathrm{msec}$ ) regardless of the frequency used. Al-Amood and Lewis (1987) kept the duration of each pulse train constant $(1 \mathrm{sec})$, while we kept the number of pulses per train constant (60); this may have contributed to the different results. For the stimulations at $100 \mathrm{~Hz}$, however, we find it very unlikely that the small difference in stimulation pattern (100 pulses at $100 \mathrm{~Hz} / 90 \mathrm{sec}$ in the experiments by AlAmood and Lewis (1987) and 60 pulses at $100 \mathrm{~Hz} / 60 \mathrm{sec}$ in our experiments) can explain why the twitch time-to-peak decreased much later and to a considerably smaller degree in the 
experiments by Al-Amood et al. (1986) and Al-Amood and Lewis (1987) than in our earlier (Lømo et al., 1974, 1980) and more recent (Hennig and Lomo, 1987a, this work; see also Eken and Gundersen, 1988) experiments. We have no satisfactory explanation for these differences in results, which lead to very different views on the mechanism behind the effects of stimulation on denervated muscle. Thus, Al-Amood and Lewis (1987) and $\mathrm{Al}$-Amood et al. (1986) propose that denervation per se induces transformation of rat SOL muscles by switching the synthesis of myosin from the slow to the fast type, whereas intermittent stimulation merely enhances this transformation by enhancing protein synthesis. In our view, neither denervation as such, nor the accompanying cessation of normal motor unit activity, is necessary for slow-to-fast transformation, since intermittent $100 \mathrm{~Hz}$ stimulation induces much faster twitches and a marked increase in the percentage of type II fibers in innervated SOL muscles that maintain their normal motor unit activity during the stimulation (Hennig and Lomo, 1987a). Similar increases in twitch speed are also seen in innervated cat SOL muscles during intermittent $100 \mathrm{~Hz}$ stimulation (Smith, 1978). In addition, we attribute the increase in twitch speed that occurs in long-term denervated SOL muscles (Finol et al., 1981; Hennig and Lomo, 1987a) to the lower amount of muscle activity after denervation, since the results presented in Figure 2 demonstrate that such reductions can lead to considerable increases in twitch speed. In conclusion, we interpret our results to mean that both the frequency and the number of impulses contribute to the regulation of contractile speed in rat SOL muscles. In addition, other characteristics of the firing patterns of motoneurons also play a role (Eken and Gundersen, 1988).

\section{Intrinsic differences between $S O L$ and EDL muscles}

Stimulation at 10 or $15 \mathrm{~Hz}$ resulted in twitches that were only half as slow in the EDL as in the SOL. The same difference in twitch speed is seen after reinnervation of the EDL and the SOL by the SOL nerve (Close, 1969; Gutmann and Carlson, 1975). In the cat, reinnervation by the SOL nerve converts original type II fibers of the flexor digitorum longus into type I fibers that are as slow as the normal, slow type I fibers in that muscle, but not as slow as the type I fibers in the SOL (Dum et al., 1985). Elsewhere we report that direct stimulation with large numbcrs of pulses at low frequency fails to convert type II fibers to type I fibers in the EDL, where $98 \%$ of the fibers remain type II during the stimulation. In contrast, in the denervated SOL, the same stimulation pattern results in $82-87 \%$ type I fibers (Gundersen et al., 1988). All of these results show that identical inputs have different effects on SOL and EDL muscles.

Intermittent high-frequency stimulation completely transformed the SOL into an EDL-like muscle with respect to the isometric twitch (Fig. 2). Elsewhere, however, it is reported that in such stimulated SOL muscles, the intrinsic $V_{\max }$ (normalized for fiber length) becomes only half as fast as that in the normal EDL (Eken and Gundersen, 1988; Gorza et al., 1988) and, furthermore, in contrast to normal EDL type II fibers, the stimulated SOL fibers continue to express slow type I myosin heavy chains, although they acquire type II myosin in addition (Gorza et al., 1988). Thus, it appears that rat SOL and EDL muscle fibers are not completely interconvertible. Resistance against complete slow-to-fast transformation is also seen in cat SOL muscles after reinnervation by fast flexor digitorum longus or medial gastrocnemius motoneurons (Dum et al., 1985; Foehring et al., 1987).
It is possible that other types of stimulation or neuronal input would have transformed the EDL and the SOL more completely. A more likely and interesting possibility, however, is that SOI. and EDL muscle fibers respond differently to similar stimulation and to reinnervation by the same nerve because they are intrinsically different. Recently, evidence for tissue-specific differences in the expression of myosin heavy chain genes has been obtained in the rat. The posterior temporalis muscle continues to express a particular "superfast" myosin heavy chain after transplantation to the leg and reinnervation there, whereas the EDL fails to express this gene after it is transplanted to the site of the posterior temporalis muscle and reinnervated there (Hoh et al., in press). In the hyperthyroid rat, expression of II A myosin heavy chain is increased in the SOL, but decreased in the EDL (Izumo et al., 1986). In chicken, there is strong evidence that fast and slow muscle fibers belong to different cell lineages (Miller and Stockdale, 1987). Therefore, an attractive possibility is that rat EDL and SOL muscle fibers also belong to different cell lineages, each having different but overlapping sets of genes "available" for expression, and each set conferring particular adaptive ranges to the muscle fibers.

In the EDL of the rabbit, slow pattern stimulation of the peroneal nerve apparently results in complete fast-to-slow transformation. In this muscle the twitch becomes even slower than the twitch of normal SOL muscles (Salmons and Sréter, 1976). In the EDL of the rat, on the other hand, the transformation is far from complete whether innervation is present or not. Therefore, intrinsic differences apparently exist not only between different muscles, such as the EDL and SOL, in the same animal, but also between homologous muscles, such as the EDL, in different species. Such differences between muscles may explain why changes in pulse rates apparently affect the twitch speed in the SOL of the rat but not in the peroneus longus of the cat. In the cat peroneus longus, intermittent $100 \mathrm{~Hz}$ stimulation does not speed up the twitch when it is added to $10 \mathrm{~Hz}$ stimulation, whereas in the rat SOL it does (Fig. $2 B$ ). Indeed, using various combinations of brief pulse trains at 10 and $100 \mathrm{~Hz}$, Eerbeek et al. (1984) and Kernell et al. (1987) find no evidence for pulse rate-specific effects on twitch speed, which appears to depend on other aspects of the treatment, such as daily amount and distribution of the stimulation. In other respects, however, the rat SOL and the cat peroneus longus respond similarly. Thus, in both muscles the twitches become slower and the tetanic tensions higher with larger pulse numbers, and the twitch/tetanus ratios become lower with higher pulse frequencies.

\section{Regulation of excitation-contraction coupling by activity}

The present results provide indirect evidence for long-term regulatory effects of cvoked muscle activity on the rate of $\mathrm{Ca}^{2+}$ release from the sarcoplasmic reticulum (SR) during a twitch and its subsequent removal from the cytosol. Thus, the longer twitch durations and lower twitch/tetanus ratios induced by increasingly larger numbers of pulses (constant frequency) can be at least partly explained by slower $\mathrm{Ca}^{2+}$ release by the $\mathrm{SR}$ and slower $\mathrm{Ca}^{2+}$ removal by $\mathrm{SR}$ and possibly parvalbumin. If the effect of the stimulation had only been to delay and slow down $\mathrm{Ca}^{2+}$ removal and not to slow down $\mathrm{Ca}^{2+}$ release, both the twitch/tetanus ratio and the twitch duration would have been expected to increase. On the other hand, the shorter twitch durations and lower twitch/tetanus ratios that were induced by increasingly higher pulse frequencies (constant number) can be explained, at least in part, by faster release and removal of $\mathrm{Ca}^{2+}$. 
Faster removal of $\mathrm{Ca}^{2+}$ may be sufficient to account for both the shorter twitch duration and the lower twitch/tetanus ratio, but since the rate of rise in twitch tension was also increased, the rate of $\mathrm{Ca}^{2+}$ release was probably increased as well. Thus, it appears that high pulse rates over time may induce faster $\mathrm{Ca}^{2+}$ release and removal, while high pulse numbers have the opposite effect.

In support of these interpretations, it has been shown that large numbers of pulses at low frequency markedly decrease $\mathrm{Ca}^{2+}$ uptake by $\mathrm{SR}$ and parvalbumin content in the cytosol both in denervated EDL muscles of the rat (Gundersen et al., 1988) and in innervated tibialis anterior muscles of the rabbit (Klug et al., 1988). Conversely, intermittent high-frequency stimulation markedly increases these parameters in the denervated rat SOL (Gundersen et al., 1988). Furthermore, during high-frequency stimulation, the SOL twitch becomes as fast as in the normal EDL, where brief depolarizations elicit considerably faster $\mathrm{Ca}^{2+}$ release and removal than they do in the normal SOL (Eusebi et al., 1980).

Chronic stimulation is unlikely, however, to affect the twitch by only affecting excitation-contraction coupling. For example, Stephenson and Williams (1981) have shown that force relaxation is faster in EDL than in SOL fibers when $\mathrm{Ca}^{2+}$ is suddenly removed from maximally activated skinned fibers, indicating that twitch duration depends not only on the kinetics of $\mathrm{Ca}^{2+}$ release and removal but also on the kinetics of force generation and relaxation by the myofilaments. Elsewhere, we have shown that intermittent $100 \mathrm{~Hz}$ stimulation induces the appearance of fast-type myosin and a higher isotonic shortening velocity in denervated rat SOL muscles, indicating faster cross-bridge cycling. But these changes appear later and are less pronounced than the changes in twitch speed, which develop rapidly after only $2 \mathrm{~d}$ of stimulation (Gorza et al., 1988). In the tibialis anterior of the rabbit, the effect on $\mathrm{Ca}^{2+}$ uptake by the SR, which is reduced to $50 \%$ of normal within $2 \mathrm{~d}$ of stimulation, is similarly rapid (Leberer et al., 1987). This suggests that excitationcontraction coupling processes and myofilament function undergo coordinated changes when activity is altered, but that excitation-contraction coupling processes, at least in rat SOL muscles, may respond faster and play a more dominating role in adapting the twitch to altered activity. This is further suggested by cross-reinnervation experiments on cat SOL muscles, where the twitch becomes much faster than normal without any corresponding changes in myosin ATPase activity and fibertype distribution (Gauthier et al., 1983).

Twitch/tetanus ratio and twitch speed for muscles or motor units are often positively correlated (e.g., Cooper and Eccles, 1930; Bagust et al., 1973; Bagust, 1974), but this is not always the case (e.g., Close, 1967; Nelson et al., 1986; this work). The present results suggest an explanation for the lack of a simple relation between twitch speed and twitch/tetanus ratio in normal muscles. When the number of pulses was kept constant, increasingly higher pulse frequencies resulted in increasingly lower twitch/tctanus ratios and fastcr twitches, suggesting that the low twitch/tetanus ratio in some fast muscles - for example, extrinsic eye muscles - may be due to the high firing rates of their motoneurons. On the other hand, when the pulse rate was kept constant, increasingly higher numbers of pulses also resulted in lower twitch/tetanus ratios, but in this case the twitches became slower. Therefore, in slow muscles the twitch/tetanus ratio may become relatively low, and thus similar to that in a fast muscle, because high impulse numbers counteract the effect of low im- pulse frequency. Furthermore, the increase in twitch/tetanus ratio induced in slow muscles by denervation (Figs. 3, 8), disuse (Fischbach and Robbins, 1969), and tenotomy (Bagust, 1979) may now be attributed, at least in part, to the reduction in the amount of activity that accompanies these procedures, whereas the increase in twitch/tetanus ratio in denervated fast muscles may be partly attributed to the absence of high-frequency activity normally imposed by fast motoneurons (Hennig and Lømo, 1985).

Duchateau and Hainaut (1986) provide evidence that activation during a twitch is not maximal and that the twitch/ tetanus ratio gives a good indication of the level of activation. In the present experiments, higher pulse rates (constant pulse number) induced faster twitches, lower twitch/tetanus ratios, and greater post-tetanic potentiations. This suggests that the level of activation during a twitch is decreased in muscles chronically stimulated at high frequency and that the increase in twitch force after a conditioning tetanus may be due to enhanced $\mathrm{Ca}^{2+}$ release. On the other hand, post-tetanic potentiation also depended on the amount of stimulation and, as a result, large differences in post-tetanic potentiation were observed without corresponding changes in twitch/tetanus ratio (Fig. 4). This is also consistent with the fact that the twitch/tetanus ratio is often found to be about the same in rat SOL and EDL muscles (Close, 1967; this work) and yet the SOL shows post-tetanic depression and the EDL post-tetanic potentiation. Thus, post-tetanic potentiation may depend not only on the level of activation, as reflected by the twitch/tetanus ratio, but also on other factors, for example, the affinity of the myofilaments for $\mathrm{Ca}^{2+}$ or other regulatory processes at the level of actomyosin. Whatever the precise processes that underlie post-tetanic potentiation, their regulation apparently depends on both the frequency and the number of impulses imposed on the muscle.

\section{Physiological adaptation to different usage or a pathological reaction to denervation and electrical stimulation?}

Jolesz and Sréter (1981) have suggested that transformation of slow muscles occurs because preexisting slow fibers degenerate and new fibers of a fast type regenerate around the stimulating electrodes. Elsewhere we conclude (Gorza et al., 1988) that this cannot explain the slow-to-fast transformation in our experiments because the denervated and stimulated SOL fibers stay large in size throughout the period of transformation, continue to bind anti-slow myosin while gradually acquiring fast myosin, and fail to bind anti-fetal myosin, which stains regenerating fibers (Sartore et al., 1982). We do see regenerating fibers in our experimental SOL muscles, as well as in our denervated and innervated control muscles, with implanted sham electrodes, but only very superficially near the electrodes. Furthermore, there is no effect of the sham electrodes on the slow-twitch speed of these control muscles (Gorza et al., 1988). In the present experiments it is likely that fibers in restricted regions of the SOL muscles were damaged and that in some muscles fibers escaped stimulation owing to faulty placement of the electrodes. But such fibers would contribute very little to the force produced by the bulk of muscle, which was well stimulated (see Fig. 6), and therefore would have little effect on the measurements of twitch speed, twitch/tetanus ratio, or post-tetanic potentiation, although they would reduce total tetanic tension to some degree.

Whereas the speed of adult SOL fibers can be markedly altered by stimulation without appearing to undergo degeneration and regeneration, this may not be the case for all types of muscle 
fibers in the EDL. In the fast EDL of the rabbit, large numbers of pulses at $10 \mathrm{~Hz}$ result in marked glycogen depletion, fiber degeneration restricted primarily to the fast glycolytic fiber population, and fiber regeneration. These degenerative/regenerative processes occur during a limited time period (approximately 6$20 \mathrm{~d}$ after onset of stimulation) and, for that reason, may be overlooked (Maier et al., 1986; Maier and Pette, 1987). A similar time course study has not been done with rat EDL muscles. However, stimulation at 10 or $15 \mathrm{~Hz}$ markedly reduced tetanic tension both in the denervated and innervated EDL (Fig. $8 D$ ) and had the same effect as denervation alone on twitch speed, suggesting that the EDL tolerates this pattern of activity poorly. During the stimulation at 10 or $15 \mathrm{~Hz}$, the EDL was kept active for 90 or $67 \%$ of the time, whereas presumed fast fatigue-sensitive motor units with fast-type glycolytic (II B) fibers in the EDL of the normal rat are active for only 0.04 to $0.2 \%$ of the time and discharge at frequencies above $40 \mathrm{~Hz}$ (Hennig and Lomo, 1987b). If type II B fibers in the rat degenerate during "tonic" stimulation at $10-15 \mathrm{~Hz}$, as they do in the rabbit, then the combined effects of an abnormally low frequency and an abnormally large amount of activity may be responsible. On the other hand, normal SOL motoncurons firc at rates ranging from about 5 to $100 \mathrm{~Hz}$ (median rate, approximately $20 \mathrm{~Hz}$ ) and for about 22 to $35 \%$ of total time (Hennig and Lømo, 1985). Since capillaries and oxidative energy systems are also well developed in rat SOL muscles, it is perhaps not surprising that this muscle tolerates a greater variety of stimulation patterns than the EDL does, and shows a wider adaptive range with regard to several contractile properties.

\section{Regulation by evoked activity or neurotrophic substances?}

Functional neuromuscular junctions also form when the conduction of nerve impulses is blocked by tetrodotoxin or other means (Jansen et al., 1973; Davey and Cohen, 1986), which shows that motoneurons influence the junctional properies of muscle fibers independently of impulse activity. Whether activity-independent factors also influence nonjunctional properties, however, remains less clear. Evidence for such factors has been obtained in the baboon where local pressure on the nerve followed by conduction blocks of up to 2 months duration results in less supersensitivity to acetylcholine than denervation (Gilliat et al., 1978). On the other hand, direct stimulation restores normal resting membrane potential, specific membrane properties, and nonjunctional sensitivity to acetylcholine in denervated rat SOL and EDL fibers (Lømo and Westgaard, 1975; Westgaard, 1975; Lomo and Gundersen, 1988), suggesting that neurotrophic substances are not essential for the regulation of these properties. Other nonjunctional properties, such as contractile speed and force, may also not require neurotrophic substances. Salviati et al. (1986) have reported that ectopic innervation by the EDL nerve induces fast myosin in SOL fibers that are also innervated by the SOL nerve. But this fast myosin is restricted to the region around the ectopic junctions, which shows that the effect is local. In other experiments, intermittent 100 $\mathrm{Hz}$ stimulation starting after several months of denervation has been shown to increase the tetanic force output of rat SOL muscles to about the same degree and along the same time course as does self-reinnervation starting after similar times of denervation (Hennig and Lømo, 1987a). In the present experiments, stimulation with pulse patterns that resemble the firing pattern of normal SOL motoneurons has the same effect on the twitch of denervated EDL and SOL muscles as does reinnervation by
SOL motoneurons. Conversely, stimulation with pulse patterns that resemble the firing pattern of EDL motoneurons has the same effect as reinnervation by EDL motoneurons (Close, 1969; Gutmann and Carlson, 1975). Furthermore, we show here that tetanic tension becomes higher in SOL muscles stimulated at high frequency than at low frequency, which may explain, at least in part, why tetanic tensions per unit of cross-sectional area are higher in EDL than in SOL muscles (Close, 1972). Although the tetanic tensions of muscles that we presume to have been "best" stimulated are up to 100 -fold greater than the tetanic tensions of denervated control muscles and sometimes come within the range of the tetanic tensions in innervated control muscles, stimulation does not, on average, prevent denervation atrophy completely. This may be due to the lack of some trophic substance, but we believe that fiber damage (see above), incomplete stimulation, or insufficient stretch by denervated flaccid antagonists are more likely explanations. In conclusion, therefore, it appears that direct stimulation can substitute for innervation for very long periods of time, and that evoked muscle activity plays a major role in the regulation of contractile properties of rat skeletal muscles.

\section{References}

Al-Amood, W. S., and D. M. Lewis (1987) The role of frequency in the effects of long-term intermittent stimulation of denervated slowtwitch muscle of the rat. J. Physiol. (Lond.) 392: 377-395.

Al-Amood, W. S., H. J. Finol, and D. M. Lewis (1986) Chronic stimulation modifies the isotonic shortening velocity of denervated rat slow-twitch muscle. Proc. R. Soc. Lond. [Biol.] 228: 43-58.

Bagust, J. (1974) Relationships between motor nerve conduction velocities and motor unit contraction characteristics in slow twitch muscle of the cat. J. Physiol. (Lond.) 238: 269-278.

Bagust, J. (1979) The effects of tenotomy upon the contraction characteristics of motor units in rabbit soleus muscle. J. Physiol. (Lond.) 290: $1-10$.

Bagust, J., S. Knott, D. M. Lewis, J. C. Luck, and R. A. Westerman (1973) Isometric contractions of motor units in a fast twitch muscle of the cat. J. Physiol. (Lond.) 231: 87-104.

Barany, M., and R. I. Close (1971) The transformation of myosin in cross-innervated rat muscles. J. Physiol. (Lond.) 213: 455-474.

Burke, R. E. (1981) Motor units: Anatomy, physiology, and functional organization. In Handbook of Physiology. The Nervous System II, pt. I, V. B. Brooks, ed., pp. 345-422, American Physiological Society, Bethesda, MD.

Burke, R. E., D. N. Levine, P. Tsairis, and F. E. Zajac (1973) Physiological types and histochemical profiles in motor units of the cat gastrocnemius. J. Physiol. (Lond.) 205: 581-597.

Close, R. (1967) Properties of motor units in fast and slow skeletal muscles of the rat. J. Physiol. (Lond.) 193: 45-55.

Close, R. (1969) Dynamic properties of fast and slow skeletal muscles of the rat after nerve cross-union. J. Physiol. (Lond.) 204: 331-346.

Close, R. I. (1972) Dynamic properties of mammalian skeletal muscles. Physiol. Rev. 52: 129-197.

Close, R., and J. F. Y Hoh (1969) Post-tetanic potentiation of twitch contractions of cross-innervated fast and slow muscles. Nature 221 : 179-181.

Cooper, S., and J. C. Eccles (1930) The isometric responses of mammalian muscles. J. Physiol. (Lond.) 69: 377-385.

Crow, M. T., and M. J. Kushmerick (1982) The relationship between initial chemical change and recovery chemical input in isolated hindlimb muscles of the mouse. J. Gen. Physiol. 79: 147-166.

Davey, D. F., and M. W. Cohen (1986) Localization of acetylcholine receptors and cholinesterase on nerve-contacted and noncontacted muscle cells grown in the presence of agents that block action potentials. J. Neurosci. 6: 673-680.

Duchateau, J., and K. Hainaut (1986) Nonlinear summation of contractions in striated muscle. I. Twitch potentiation in human muscle. J. Muscle Res. Cell Motil. 7: 11-17.

Dum, R. P., M. J. O'Donovan, J. Toop, and R. E. Burke (1985) Crossreinnervated motor units in cat muscle. I. Flexor digitorum longus 
muscle reinnervated by soleus motoneurons. J. Neurophysiol. 54: 818-836.

Eerbeek, O., D. Kernell, and B. A. Verhey (1984) Effects of fast and slow patterns of tonic long-term stimulation on contractile properties of fast muscle in the cat. J. Physiol. (Lond.) 352: 73-90.

Eken, T., and K. Gundersen (1988) Chronic electrical stimulation resembling normal motor-unit activity: Effects on denervated fast and slow rat muscles. J. Physiol. (Lond.) 402: 651-669.

Eusebi, F., R. Miledi, and T. Takahashi (1980) Calcium transients in mammalian muscles. Nature 284: 560-561.

Finol, H. S., D. M. Lewis, and R. Owens (1981) The effects of denervation on contractile properties of rat skeletal muscle. J. Physiol. (Lond.) 319: 81-92.

Fischbach, G., and N. Robbins (1969) Changes in contractile properties of disused soleus muscles. J. Physiol. (Lond.) 201: 305-320.

Foehring, R. C., G. W. Sypert, and J. B. Munson (1987) Motor-unit properties following cross-reinnervation of cat lateral gastrocnemius and soleus muscles with medial gastrocnemius nerve. II. Influence of muscle on motoneurons. J. Neurophysiol. 57: 1227-1245.

Gallego, R., P. Huizar, N. Kudo, and M. Kuno (1978) Disparity of motoneuron and muscle differentiation following spinal cord transection in the kitten. J. Physiol. (Lond.) 281: 253-265.

Gauthier, G. F., R. E. Burke, S. Lowey, and A. W. Hobbs (1983) Myosin isozymes in normal and cross-reinnervated cat skeletal muscles. J. Cell Biol. 97: 756-771.

Gilliat, R. W., R. H. Westgaard, and I. R. Williams (1978) Extrajunctional acetylcholine sensitivity of inactive muscle fibres in the baboon during prolonged nerve pressure block. J. Physiol. (Lond.) 280: 499-514.

Gorza, L., K. Gundersen, T. Lømo, S. Schiaffino, and R. H. Westgaard (1988) Slow to fast transformation of denervated soleus muscles by chronic high frequency stimulation in the rat. J. Physiol. (Lond.) 402: 627-649.

Gundersen, K., E. Leberer, T. Lomo, D. Pette, and R. S. Staron (1988) Fiber types, calcium-sequestering proteins and metabolic enzymes in denervated and chronically stimulated muscles of the rat. J. Physiol. (Lond.) 398: 177-189.

Guth, L., and J. B. Wells (1972) Physiological and histochemical properties of the soleus muscle after denervation of its antagonists. Exp. Neurol. 36: 463-471.

Gutmann, E., and B. M. Carlson (1975) Contractile and histochemical properties of regenerating cross-transplanted fast and slow muscles in the rat. Pfluegers Arch. 353: 227-239.

Hennig, R. (1987) Section of fibular nerve affects activity pattern and contractile properties of soleus motor units in adult rats. Acta Physiol. Scand. 130: 143-151.

Hennig, R., and T. Lamo (1985) Firing patterns of motor units in normal rats. Nature $314: 164-166$.

Hennig, R., and T. Lømo (1987a) Effects of chronic stimulation on the size and speed of long-term denervated and innervated rat fast and slow skeletal muscles. Acta Physiol. Scand. 130: 115-131.

Hennig, R., and T. Lomo (1987b) Gradation of force output in normal fast and slow muscles of the rat. Acta Physiol. Scand. 130: 133-142.

Hoh, J. F. Y., S. Hughes, P. Hale, C. Chow, R. Fitzsimons, and S. Schiaffino (in press) Nerve-independent phenotypic differences between cat jaw and limb muscles. In Adaptive Mechanisms of Muscle, F. Guba, ed., Publishing House of the Hungarian Academy of Science, Budapest.

Izumo, S., B. Nadal-Ginard, and V. Mahdavi (1986) All members of the MHC multigene family respond to thyroid hormone in a highly tissue-specific manner. Science 231: 597-600.

Jansen, J. K. S., T. Lomo, K. Nicolaysen, and R. H. Westgaard (1973) Hyperinnervation of skeletal muscle fibers: Dependence on muscle activity. Science $181: 559-561$.

Jolesz, F., and F. A. Sréter (1981) Development, innervation, and activity-pattern induced changes in skeletal muscle. Annu. Rev. Physiol. 43: 531-552.

Kernell, D. (1979) Rhythmic properties of motoneurones innervating muscle fibers of different speed in $\mathrm{m}$. gastrocnemius medialis of the cat. Brain Res. 160: 159-162.
Kernell, D., O. Eerbeek, B. A. Verhey, and Y. Donselaar (1987) Effects of physiological amounts of high- and low-rate chronic stimulation on cat's fast muscle. 1. Speed- and force-related properties. J. Neurophysiol. 58: 598-613.

Klug, G. A., E. Leberer, E. Leisner, J.-A. Simoneau, and D. Pette (1988) Relationship between parvalbumin content and the speed of relaxation in chronically stimulated rabbit fast-twitch muscle. Pfluegers Arch. 411: 126-131.

Leberer, E., K.-T. Härtner, and D. Pette (1987) Reversible inhibition of sarcoplasmic reticulum Ca-ATPase by altered neuromuscular activity in rabbit fast-twitch muscle. Eur. J. Biochem. 162: 555-561.

Lomo, $T$. (1976) 'The role of activity in the control of membrane and contractile properties of skeletal muscle. In Motor Innervation of Muscle, S. Thesleff, ed., pp. 289-321. Academic, London.

Lømo, T., and K. Gundersen (1988) Trophic control of skeletal muscle membrane properties. In Nerve-Muscle Cell Trophic Communication, H. L. Fernandez and J. A. Donoso, eds., pp. 61-79, CRC, Boca Raton, FL.

Lomo, T., and R. H. Westgaard (1975) Further studies on the control of ACh sensitivity by muscle activity in the rat. J. Physiol. (Lond.) 252: $603-626$.

Lømo, T., R. H. Westgaard, and H. A. Dahl (1974) Contractile properties of muscle: Control by pattern of muscle activity in the rat. Proc. R. Soc. Lond. [Biol.] 187: 99-103.

Lømo, T., R. H. Westgaard, and L. Engebretsen (1980) Different stimulation patterns affect contractile properties of denervated rat soleus muscles. In Plasticity of Muscle, D. Pette, ed., pp. 297-309, Walter de Gruyter, Berlin.

Maier, A., and D. Pette (1987) The time course of glycogen depletion in single fibers of chronically stimulated rabbit fast-twitch muscle. Pfluegers Arch. 408: 338-342.

Maier, A., B. Gambke, and D. Pette (1986) Degeneration-regeneration as a mechanism contribution to the fast to slow conversion of chronically stimulated fast-twitch rabbit muscle. Cell Tissue Res. 244: 635643.

Mayer, R. F., R. E. Burke, J. Toop, J. A. Hodgson, K. Kanda, and B. Walmsley (1981) The effect of long-term immobilization on the motor unit population of the cat medial gastrocnemius muscle. Neuroscience 6: 725-739.

Mayer, R. F., R. E. Burke, J. Toop, B. Walmsley, and J. A. Hodgson (1984) The effect of spinal cord transection on motor units in cat medial gastrocnemius muscles. Muscle Nerve 7: 23-31.

Miller, J. B., and F. E. Stockdale (1987) What muscle cells know that nerve cells don't tell them. Trends Neurosci. 10: 325-329.

Nelson, J. S., S. J. Goldberg, and I. R. McClung (1986) Motoneuron electrophysiological and muscle contractile properties of superior oblique motor units in cat. J. Neurophysiol. 55: 715-726.

Pette, D., M. E. Smith, H. W. Staudte, and G. Vrbová (1973) Effects of long-term electrical stimulation or some contractile and metabolic characteristics of fast rabbit muscles. Pfluegers Arch. 338: 252-272.

Salmons, S., and F. A. Sréter (1976) Significance of impulse activity in the transformation of skeletal muscle type. Nature 263: 30-34.

Salmons, S., and G. Vrbová (1969) The influence of activity on some contractile properties of mammalian fast and slow muscles. J. Physiol. (Lond.) 210: 535-549.

Salviati, G., E. Biasia, and M. Aloisi (1986) Synthesis of fast myosin induced by fast ectopic innervation of rat soleus muscle is restricted to the ectopic endplate region. Nature 322: 637-639.

Sartore, S., L. Gorza, and S. Schiaffino (1982) Fetal myosin heavy chains in regenerating muscle. Nature 298: 294-296.

Smith, D. M. (1978) Miniature stimulator for chronic animals. Pfluegers Arch. 376: 93-95.

Stephenson, D. G., and D. A. Williams (1981) Calcium-activated force responses in fast- and slow-twitch skinned muscle fibers of the rat at different temperatures. J. Physiol. (Lond.) 317: 281-302.

Westgaard, R. H. (1975) Influence of activity on the passive electrical properties of denervated soleus muscle fibres in the rat. J. Physiol. 251: $683-697$. 